\title{
The high cost burden of third- to fifth-line treatments for multiple myeloma: unsustainable and unaffordable
}

\author{
Chelsee Jensen, PharmD
}

The cost of multiple myeloma (MM) therapy continues to increase because of the approval of highcost medications by the US Food and Drug Administration (FDA). The Institute of Clinical and Economic Review (ICER) Midwest Comparative Effectiveness Public Advisory Council recently evaluated the cost-effectiveness of 3 new immunotherapy treatments for MM: belantamab mafodotin-blmf (Blenrep), chimeric antigen receptor T-cell (CAR-T) therapy idecabtagene vicleucel (ide-cel; Abecma), and ciltacabtagene autoleucel (ciltacel). ${ }^{1}$ According to the ICER evaluation, CAR- $T$ therapies prevail in the multirefractory setting based on superior overall response rates, but it recommended a $50 \%$ discount to the current list price of ide-cel to meet the $\$ 100,000$ per quality-adjusted lifeyear gained threshold. ${ }^{1}$ Belantamab is within the cost-effectiveness threshold compared with other triple- or penta-refractory comparators, but confirmation of overall survival data and management of visual side effects must be better understood. ${ }^{1}$ To interpret the recommendations, it is important to consider them in the context of cumulative financial burden on MM patients and payers for drug therapy and toxicity management, once they reach later line therapies.
Table 1 outlines Medicare and patient costs for common firstthrough fifth-line therapies for nontransplant eligible MM patients, with emphasis on the highest cost drug within the regimen and excludes manufacturer discounts or rebates. ${ }^{2}$ Using the Medicare Part D 2020 standard drug benefit design, patients prescribed oral therapies billed through Part D would enter the "doughnut hole" by the second month of therapy. Medicare Part D patients prescribed high-cost medications would reach their out-of-pocket (OOP) maximums, with Medicare covering the remainder. ${ }^{3-5}$

Patients with Medicare are not eligible for copay coupons; many are on a fixed income and most likely are not able to sustainably pay these costs when advancing through multiple lines of treatment. There is no OOP maximum for Medicare Part B, but recognizing these high costs, it is presumed that most patients will have a Medicare supplement insurance (Medigap), which is not accounted for in Table $1 .{ }^{6}$ Fortunately, there may be some relief for patients and payers when patent exclusivity expires and generic competition can occur for lenalidomide (Revlimid) in 2022, carfilzomib (Kyprolis) in 2027, daratumumab (Darzalex; intravenous)

\begin{abstract}
Author affiliations
Chelsee Jensen, PharmD, Instructor of Pharmacy, Pharmaceutical Formulary Manager, Department of Finance, Mayo Clinic, Rochester, MN.

AUTHOR CORRESPONDENCE:

Chelsee Jensen, jensen.chelsee@mayo.edu

J Manag Care Spec Pharm. 2021;27(9):1321-24

Copyright $\odot 2021$, Academy of Managed Care Pharmacy. All rights reserved.
\end{abstract}

in 2029, and daratumumab and hyaluronidase-fihj (Darzalex Faspro; subcutaneous) in 2036 . $^{7}$

ICER notes that belantamab has comparable or slightly superior overall survival with fifth-line comparators at 13.8 months vs 9.2 months and 5.6 months for triple-, quad-, and penta-refractory patients, respectively. ${ }^{1}$ However, belantamab's ocular toxicity risk and resultant payer and patient costs for Risk Evaluation and Mitigation Strategy (REMS) program requirements cannot not be overlooked. ${ }^{1,8}$ Patients may prefer selinexor plus dexamethasone in the fifth-line setting because of oral therapy, less time traveling to an infusion center, 


\section{TABLE 1 Medicare and Patient Costs for Common First- Through Fifth-Line Therapies for Nontransplant-Eligible Multiple Myeloma}

\begin{tabular}{|c|c|c|c|c|c|c|c|c|c|}
\hline $\begin{array}{l}\text { Patient } \\
\text { type }\end{array}$ & Stage $^{2}$ & Regimen $^{a}$ & $\begin{array}{c}\text { Most } \\
\text { expensive } \\
\text { drugs in regimen }\end{array}$ & $\begin{array}{c}\text { Annual cost } \\
\text { to Medicare } \\
\text { (M) })^{5,18,19, b}\end{array}$ & $\begin{array}{c}\text { Estimated } \\
\text { patient } \\
\text { medical } \\
\text { expenses }^{\mathrm{c}}\end{array}$ & $\begin{array}{c}\text { Annual cost } \\
\text { to Medicare } \\
(P)^{18,19, b, d}\end{array}$ & $\begin{array}{l}\text { Annual OOP } \\
\text { pharmacy } \\
\text { costs } \\
\text { (standard } \\
\text { Medicare } \\
\text { Part D) }\end{array}$ & $\begin{array}{l}\text { Annual } \\
\text { cumulative } \\
\text { cost to } \\
\text { Medicare for } \\
\text { regimen } \\
\text { (M\& \&) }\end{array}$ & $\begin{array}{l}\text { Annual } \\
\text { cumulative } \\
\text { patient OOP } \\
\text { expenses for } \\
\text { regimen } \\
\text { (M \& P) }\end{array}$ \\
\hline \multirow{10}{*}{$\begin{array}{l}\text { Non- } \\
\text { transplant } \\
\text { eligible: } \\
\text { traditional } \\
\text { Medicare } \\
\text { insurance }\end{array}$} & First line & VRd & $\begin{array}{c}\text { Bortezomib (M) } \\
\text { Lenalidomide }(P)\end{array}$ & $\$ 33,523$ & $\$ 6,705$ & $\$ 231,397$ & $\$ 9,719$ & $\$ 248,496$ & $\$ 16,424$ \\
\hline & First line & DRd & $\begin{array}{c}\text { Daratumumab SC (M) } \\
\text { Lenalidomide }(\mathrm{P})\end{array}$ & $\$ 183,645$ & $\$ 36,729$ & $\$ 231,397$ & $\$ 9,719$ & $\$ 368,594$ & $\$ 46,448$ \\
\hline & First line & $\mathrm{KRd}$ & $\begin{array}{l}\text { Carfilzomib }(\mathrm{M}) \\
\text { Lenalidomide }(\mathrm{P})\end{array}$ & $\$ 34,667$ & $\$ 6,933$ & $\$ 231,397$ & $\$ 9,719$ & $\$ 249,412$ & $\$ 16,652$ \\
\hline & $\begin{array}{l}\text { Second } \\
\text { line }\end{array}$ & $\mathrm{DVd}^{20}$ & $\begin{array}{c}\text { Bortezomib (M) } \\
\text { Daratumumab SC (M) }\end{array}$ & $\$ 206,681$ & $\$ 41,336$ & $\mathrm{~N} / \mathrm{A}$ & $\mathrm{N} / \mathrm{A}$ & $\$ 165,345$ & $\$ 41,336$ \\
\hline & $\begin{array}{l}\text { Second } \\
\text { line }\end{array}$ & SVd & $\begin{array}{c}\text { Bortezomib }(M) \\
\text { Selinexor }(P)\end{array}$ & $\$ 51,792$ & $\$ 10,358$ & $\$ 332,323$ & $\$ 9,719$ & $\$ 364,038$ & $\$ 20,077$ \\
\hline & Fifth line & $\mathrm{N} / \mathrm{A}$ & Melphalan flufenamide (M) & $\$ 234,840$ & $\$ 46,968$ & $\mathrm{~N} / \mathrm{A}$ & $\mathrm{N} / \mathrm{A}$ & $\$ 187,872$ & $\$ 46,968$ \\
\hline & Fifth line & $\mathrm{N} / \mathrm{A}$ & Ide-cel (M) & $\$ 432,085$ & $\$ 86,417$ & $\mathrm{~N} / \mathrm{A}$ & $\mathrm{N} / \mathrm{A}$ & $\$ 345,668$ & $\$ 86,417$ \\
\hline & Stage $^{2}$ & Regimen $^{a}$ & $\begin{array}{c}\text { Most } \\
\text { expensive } \\
\text { drugs in regimen }\end{array}$ & $\begin{array}{l}\text { Cost to } \\
\text { Medicare } \\
\text { (based on } \\
\text { mDOT) } \\
\end{array}$ & $\begin{array}{c}\text { Estimated } \\
\text { medical } \\
\text { expenses }\end{array}$ & $\begin{array}{l}\text { Cost to } \\
\text { Medicare } \\
(P)^{18}\end{array}$ & $\begin{array}{c}\text { OOP } \\
\text { pharmacy } \\
\text { costs } \\
\text { (standard } \\
\text { Medicare } \\
\text { Part D) }\end{array}$ & $\begin{array}{l}\text { Cumulative } \\
\text { cost to } \\
\text { Medicare for } \\
\text { regimen } \\
\text { (M \& P) }\end{array}$ & $\begin{array}{l}\text { Cumulative } \\
\text { patient OOP } \\
\text { expenses for } \\
\text { regimen } \\
\text { (M\& P) }\end{array}$ \\
\hline & Fifth line ${ }^{8}$ & $\mathrm{~N} / \mathrm{A}$ & Belantamab (M) & $\$ 54,658$ & $\$ 10,932$ & $\mathrm{~N} / \mathrm{A}$ & $\mathrm{N} / \mathrm{A}$ & $\$ 43,726$ & $\$ 10,932$ \\
\hline & Fifth line ${ }^{9}$ & $\mathrm{Sd}$ & Selinexor $(P)$ & $\mathrm{N} / \mathrm{A}$ & $\mathrm{N} / \mathrm{A}$ & $\$ 110,744$ & $\$ 9,719$ & $\$ 110,744$ & $\$ 9,719$ \\
\hline
\end{tabular}

${ }^{a}$ Regimens containing daratumumab can use intravenous daratumumab (Darzalex) or subcutaneous daratumumab (Darzalex Faspro); Subcutaneous daratumumab costs were used in this table, since the WAC for subcutaneous therapy is only marginally more than the intravenous therapy and offers shorter infusion times, which is convenient for patients and offers efficiency for cancer infusion centers. ${ }^{8}$

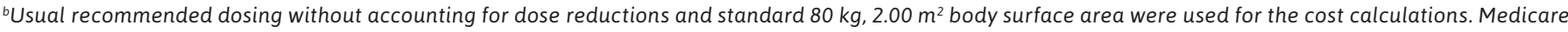
Part B reimburses based on ASP plus $6 \%$ or WAC plus $3 \%$ when ASP is not yet established.

'Estimated patient medical expenses are $20 \%$ of annual cost to Medicare (M) column.

${ }^{d}$ The mean point of sale price per 1-month fill of lenalidomide filled through Medicare Part D in 2018 was $\$ 21,412.18 .5$

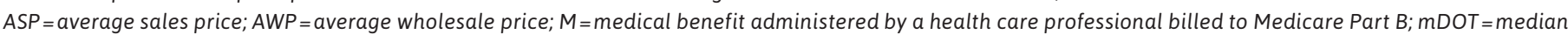

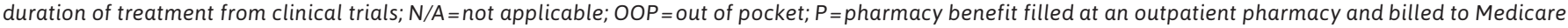
Part D; $\mathrm{SC}=$ subcutaneous; $W A C=$ wholesale acquisition cost.

no ocular side effects other than the risk of cataract associated with dexamethasone, and possibly lower OOP costs (Table 1). ${ }^{9}$ Payers must weigh overall response rates, progression-free survival, ancillary costs from administration and toxicity management, and adherence when considering formulary status for these 2 fifth-line agents.

While ide-cel and cilta-cel have impressive response rates compared with usual care and belantamab at $63 \%$, $75 \%, 31 \%$, and $32 \%$, respectively, and comparable median progression-free survival at 8.6 months and 12.4 months for ide-cel and cilta-cel, respectively, the cumulative financial burden already absorbed by the patient and payer from earlier lines of therapy is substantial. ${ }^{1}$ While cilta-cel is not yet approved by the FDA, launching at the ICER recommended threshold of $\$ 200,000$ would improve access and pressure ide-cel's manufacturer to lower its list price. Presumably most payers will only cover 1 infusion/dose of CAR-T for cost containment purposes. Yet payers should pursue value-based contracts for CAR-T therapies and ensure that the costs for cytokine release syndrome management (eg, tocilizumab and intensive care days) are negotiated within the value-based arrangement. Close monitoring of the uptake of CAR-T therapy by prescribers, patients, and payers and clinical trials of CAR-T in earlier lines of therapy will be informative. 
While not mentioned in the ICER review, melphalan flufenamide (Pepaxto) was approved by the FDA in February 2021 for relapsed/refractory MM after 4 or more lines of therapy (Table 1)..$^{10}$ Unfortunately, there are no trials comparing melphalan flufenamide with more inexpensive conventional alkylating agents such as cyclophosphamide and melphalan. I would challenge payers to encourage clinical trial participation for MM patients, particularly at low-income referral centers and for underserved populations, that compare outcomes, safety, and total cost of care for melphalan flufenamide vs melphalan or cyclophosphamide. Furthermore, outcomes, toxicity management, and total cost of care comparisons between melphalan flufenamide and belantamab in the fifth-line setting should be studied.

As ICER recommends, all stakeholders need to increase efforts to enroll African American patients in clinical trials and moderate new treatment pricing to improve affordability. ${ }^{1}$ Patients who are African American are twice as likely to have MM compared with patients who are White. Enrollment of African American patients are low in recent trials for later line therapies, accounting for $17 \%$ of patients in the DREAMM-2 trial for belantamab, $16 \%$ of patients in the STORM trial for selinexor (Xpovio), $6 \%$ of patients enrolled in the ide-cel trials, and $6 \%$ in the HORIZON study for melphalan flufenamide. ${ }^{1,8-11}$ Recognizing that historical mistreatment of patients who are African American may be a barrier to clinical trial participation, providers need to educate patients about human subjects research protections..$^{12}$

Future policy should focus on manufacturer-sponsored postmarketing trials in minority groups that were underrepresented within preapproval trials. Adequate reimbursement to the center performing the clinical trial should be an area of focus for health care policy reform to promote clinical trial programs at centers that serve low-income and high-risk communities to close racial and socioeconomic gaps.

With respect to ICER's recommendations to Medicare, value-based payment structures, including outcomes-based measures and real-world evidence, must unequivocally be considered for future policy. ${ }^{1}$ The costs of treatments to manage toxicities should be factored into the value-based payment structures, since these costs are substantial and affect quality of life. For incurable diseases such as MM, the FDA and Centers for Medicare \& Medicaid Services should be able to negotiate sale prices based on the incremental value provided by the drug. ${ }^{13}$ This concept should also be applied to medications granted accelerated approval by the FDA. If such negotiations are allowed, Medicare patients should not be excluded from using copay coupons. The clinical research community should consider studies funded by the National Institutes of Health (NIH) to evaluate treatment holidays, effect on outcomes, costs, and patient-reported quality of life. ${ }^{1}$ Drugs that have been funded in part by the NIH should be reevaluated and priced at a discount at minimum to government-funded programs and potentially commercial programs.

As ICER also recommended, prescribing tools, algorithms, and the development of cost-effective care pathways can help guide prescribers and financial counselors when having treatment discussions with patients, in addition to increased availability and affordability of cytogenetic testing, which facilitates treatment selection. ${ }^{1}$ Payers should team with the National Comprehensive Cancer Network (NCCN) and other institutions to create care pathways for NCCN-endorsed category 1 treatment pathways, incentivizing patients to these pathways by lowering direct costs and having a set, fair market, reimbursement structure for institutions.

Although Table 1 focuses primarily on Medicare, average wholesale price was used to demonstrate the highly inflated price tag that makes coinsurance and deductibles unaffordable, especially for uninsured and self-pay patients. Private insurers pay $141 \%-259 \%$ of Medicare rates for all hospital services; patients with employer-sponsored insurance were $44 \%$ more likely to report not taking a medication because of the cost and 192\% more likely to have medical debt compared with Medicare patients. ${ }^{14,15}$

ICER recommends that manufacturers price novel treatments that align with the patient-centered therapeutic value. ${ }^{1}$ Novel therapies should be priced low at product launch, and then the price can increase as real-world evidence of benefit is gained or, in the case of medications granted accelerated approval by the FDA, until stage 4 confirmatory trials are complete. Costs to manage toxicities must be factored in when pricing novel therapies, since they contribute to the cumulative treatment cost. Adding cost-effectiveness as a secondary endpoint for trials with later line therapies should become standard, especially as it relates to incurable diseases. ${ }^{13}$

Future health care reform policies should address "ever-greening" and other patent-extending tactics by manufacturers that go beyond the 20 years intended by US patent law. Federally funded insurance programs should receive the product at a cost that is discounted in a similar trend to drugs that experience generic competition from multiple manufacturers. ${ }^{16,17}$ In this framework, it is pertinent that facilities administering these therapies are reimbursed sufficiently across the continuum of care. 
If the federal government would incentivize companies to produce products using the supplemental biologic license application (sBLA) and abbreviated new drug application (ANDA) pathways, the availability of cheaper drugs could increase, and pay-for-delay strategies would become less advantageous to followon companies..$^{15}$ Encouraging nonprofit companies, such as CivicaRx, to develop these cheaper alternatives would help mitigate drug shortages, improve access to care, and lower costs to patients and payers.

In conclusion, third- to fifth-line treatments for MM are unaffordable and unsustainable for patients and payers. Efforts need to be made to moderate list prices for new medications, create cost-effective care pathways, enroll at-risk populations in clinical trials, and increase market competition to improve US health care sustainability.

\section{DISCLOSURES}

No funding was provided for the writing of this commentary. In this commentary, the author refers to CivicaRx, for which Mayo Clinic is a founding member. As an employee of Mayo Clinic, the author does not have any direct financial relationship with or support from CivicaRx.

\section{REFERENCES}

1. Lee SJ, McQueen RB, Beinfeld M, et al. Anti B-cell maturation antigen CAR T-cell and antibody drug conjugate therapy for heavily pre-treated relapsed and refractory multiple myeloma. Final evidence report. Institute for Clinical and Economic Review. May 11, 2021. Accessed May 12 , 2021. https://icer.org/wp-content/ uploads/2020/10/ICER MultipleMyeloma_Final-Report_Update_070921. pdf
2. National Comprehensive Cancer Network. Multiple myeloma (version 7.2021). 2021. Accessed June 14, 2021. https://www.nccn.org/professionals/ physician_gls/pdf/myeloma.pdf

3. Desai R, Kraus A, Gurley K. USA. In: Pricing \& Reimbursement 2020. Global Legal Group; 2020. Accessed May 19, 2021. https://www.globallegalinsights. com/practice-areas/pricing-andreimbursement-laws-and-regulations / usa

4. Wolters Kluwer Health. Revlimid, Darzalex Faspro, Kyprolis, Xpovio, Pepaxto, Abecma, Blenrep. Medi-Span Price Rx. Database. Updated May 19, 2021. Accessed May 19, 2021. 4. https://pricerx. medispan.com/Refresh/Login.aspx

5. Dusetzina SB. Specialty drug pricing and out-of-pocket spending on orally administered anticancer drugs in Medicare Part D, 2010 to 2019. JAMA. 2019;321(20):2025-27.

6. Healthline Media. Understanding Medicare out-of-pocket maximums. 2020. Accessed June 14, 2021. https://www. healthline.com/health/medicare/medicare-out-of-pocket-maximum\#takeaway

7. IPD Analytics. Life-cycle insights. March 2021. Accessed May 19, 2021. https:// www.ipdanalytics.com

8. Lonial S, Lee H, Badros A, et al. Belantamab mafodotin fir relapsed or refractory multiple myeloma (DREAMM-2): a two-arm, randomised, open-label, phase 2 study. Lancet Oncol. 2020;21(2):207-21. doi: 10.1016/ S1470-2045(19)30788-0

9. Xpovio (selinexor). Package insert. Karyopharm Therapeutics Inc; 2021. Accessed August 17, 2021. https:// www.karyopharm.com/wp-content/ uploads/2019/07/NDA-212306-SN-0071Prescribing-Information-01July2019.pdf

10. Pepaxto (melphalan flufenamide). Package insert. Oncopeptides Inc; 2021. Accessed August 17, 2021. https://www. accessdata.fda.gov/drugsatfda_docs/ label/2021/214383s000lbl.pdf
11. Abecma (idecabtagene vicleucel). Package insert. Celgene Co; 2021. Accessed August 17, 2021. https://packageinserts.bms.com/pi/pi_abecma.pdf

12. Washington, Harriet A. Medical Apartheid: The Dark History of Medical Experimentation on Black Americans from Colonial Times to the Present. Doubleday; 2006.

13. Rajkumar SV, Harousseau JL. Nextgeneration multiple myeloma treatment: a pharmacoeconomic perspective. Blood. 2016;128(4):2757-64.

14. Lopez E, Neuman T, Jacobson G, Levitt L. How much more than Medicare do private insurers pay? A review of the literature. Kaiser Family Foundation. April 2020. Accessed June 17, 2021. https:// www.kff.org/medicare/issue-brief/howmuch-more-than-medicare-do-privateinsurers-pay-a-review-of-the-literature/

15. Wray CM, Khare M, Keyhani S. Access to care, cost of care, and satisfaction with care among adults with private and public health insurance in the US. JAMA Netw. 2021;4(6):e2110275.

16. Rogers DL. Double patenting: followon pharmaceutical patents that suppress competition. Northwest J Technol Intellect Prop. 2017;14(3):317-80. Accessed June 17, 2021. https://scholarlycommons.law. northwestern.edu/njtip/vol14/iss3/3

17. I-MAK. Overpatented, overpriced: how excessive pharmaceutical patenting is extending monopolies and driving up drug prices. 2018. Accessed June 17, 2021. https://www.i-mak.org/wp-content/ uploads/2018/08/I-MAK-OverpatentedOverpriced-Report.pdf

18. Wolters Kluwer. Medi-Span PriceRx Pro Online. Database. Accessed May 19, 2021. https://www.wolterskluwer.com/ en/solutions/medi-span/price-rx

19. IPD Analytics. Codesource. Accessed June 14, 2021. https://www.ipdanalytics. com/coding-reimbursement

20. Palumbo A, Chanan-Khan A, Weisel K, et al. Daratumumab, bortezomib, and dexamethasone for multiple myeloma. N Engl J Med. 2016;375(8):75466. doi: 10.1056/NEJMoa1606038 